\title{
The Rise of Apomixis in Natural Plant Populations
}

\section{Diego Hojsgaard ${ }^{* \dagger}$ and Elvira Hörandl*t}

Department of Systematics, Biodiversity and Evolution of Plants (with Herbarium), Albrecht-von-Haller Institute for Plant Sciences, University of Göttingen, Göttingen, Germany

Apomixis, the asexual reproduction via seed, has many potential applications for plant breeding by maintaining desirable genotypes over generations. Since most major crops do not express natural apomixis, it is useful to understand the origin and maintenance of apomixis in natural plant systems. Here, we review the state of knowledge on origin, establishment and maintenance of natural apomixis. Many studies suggest that hybridization, either on diploid or polyploid cytotypes, is a major trigger for the formation of unreduced female gametophytes, which represents the first step toward apomixis, and must be combined to parthenogenesis, the development of an unfertilized egg cell. Nevertheless, fertilization of endosperm is still needed for most apomictic plants. Coupling of these three steps appears to be a major constraint for shifts to natural apomixis. Adventitious embryony is another developmental pathway toward apomixis. Establishment of a newly arisen apomictic lineage is often fostered by sideeffects of polyploidy. Polyploidy creates an immediate reproductive barrier against the diploid parental and progenitor populations; it can cause a breakdown of genetic selfincompatibility (SI) systems which is needed to establish self-fertility of pseudogamous apomictic lineages; and finally, polyploidy could indirectly help to establish an apomictic cytotype in a novel ecological niche by increasing adaptive potentials of the plants. This step may be followed by a phase of diversification and range expansion, mostly described as geographical parthenogenesis. The utilization of apomixis in crops must consider the potential risks of pollen transfer and introgression into sexual crop fields, which might be overcome by using pollen-sterile or cleistogamous variants. Another risk is the escape into natural vegetation and potential invasiveness of apomictic plants which needs careful management and consideration of ecological conditions.

Keywords: apomictic crops, grass cultivars, polyploidy, reproductive assurance, sexuality, speciation, triploid bridge

\section{INTRODUCTION}

Sexuality is well entrenched in all seed producing plants. Seeds are an integral part of diaspores that enhance plant dispersals and store all nutrients needed to start the new generation. Therefore, a wide variety of insects, animals and men found food resources in many plant seeds. The development of human societies is tightly linked to the domestication and improvement of crop

Abbreviations: $\mathrm{B}_{I I I}$ hybrid, offspring produced by fertilization of unreduced egg cells; CitRWP, a RWP-RK domaincontaining protein found in citrus; FCSS, flow cytometric seed screen; MC, megaspore; MMC, megaspore mother cell; NC, nucellus cell; PHERES1, a transcription factor encoded by a MADS-box gene; SC, self-compatibility. 
species through artificial selection and genetic breeding (see e.g., Gupta, 2004). Both traditional and molecular plant breeding techniques are designed to modify and exploit sexuality to create new heterozygous seed varieties with desired allele combinations for high yield, resistance to different environmental stressors, or nutritionally enriched seeds (e.g., golden rice; see Dirks et al., 2009). However, the same sexual mechanisms that are manipulated to improve plant varieties (e.g., engineering meiosis by reverse breeding) are simultaneously the ones responsible for diminishing heterozygosity and segregating successful gene combinations (Lambing et al., 2017).

The formation of a seed involves a number of complex developmental steps, highly regulated and coordinated that still are not well understood (Bradford and Nonogaki, 2007). Sexual seed development is initiated by the process of double fertilization, which involves the fusion of reduced female and male gametes and leads to the development of the embryo and the endosperm (Figure 1). The hormone auxin has a crucial role during the initial development of seed structures and as a trigger of fertilization-independent seed development (Figueiredo and Kohler, 2018), a condition that occurs naturally in (apomictic) plants at low frequencies. Apomicts have evolved mechanisms that circumvent sexual pathways (Figure 1) by forming functional female gametophytes without meiosis (apomeiosis), developing embryos without fertilization (parthenogenesis), and a functional endosperm. Unreduced gametophytes can develop via two main developmental pathways: (1) two unreduced MCs are formed via restitutional meiosis or via mitotic division (diplospory); (2) a somatic, unreduced cell of the nucellus develops into an embryo sac (apospory). Although gamete fusion is a strict requirement for initiation of seed development in nature, apomictic plants can produce seeds through a single fertilization of the polar nuclei (pseudogamy) or without fertilization (autonomously) (Figure 1). Therefore, seed development without fertilization represents a trait of high economic relevance to exploit heterosis and preserve superior allele combinations (Koltunow and Grossniklaus, 2003). Synthetic clonal seed production had been exercised in both Arabidopsis and rice, aiming at introducing apomixis-like features into crops (Marimuthu et al., 2011; Mieulet et al., 2016). However, while cultivated crops are expected to be genetically uniform in a similar way to apomictic clonemates, the introduction of apomixis in crop fields might bring new ecological threats derived from the biological advantages apomictic plants show compared to sexual ones (e.g., uniparental reproduction, unidirectional gene transfer; Hörandl, 2006). The escape of an apomixis gene into a wild relative may provide immediate invasive-like features to the recipient individual, but also other unintended (i.e., pleiotropic) benefits like increased fitness or pathogen resistance already observed in cases of crop $\mathrm{x}$ wild hybridizations (Chapman and Burke, 2006).

Before speculating about the biosafety and ecology of a potential apomictic crop, we can gain comparable valuable information from observations in natural apomictic plant populations. Apomicts exhibit a variety of developmental alternatives to bypass sexual pathways and produce clonal seeds (Figure 1). In single ovules, apomicts might use both sexual and apomictic seed development alternately (only one pathway proceed; Figures 1a,b) or even simultaneously (either both pathways proceed or are combined forming a $\mathrm{B}_{I I I}$; Figures 1d,e). Understanding the dynamics of apomixis in natural populations can provide useful information to know how an apomictic crop may behave in natural fields and visualize potential ecological threats. In recent years, the use of different technologies had enlarged our understanding of the genetic and developmental basis of apomixis in different plant species (Ozias-Akins and van Dijk, 2007; Conner et al., 2015; Hojsgaard and Hörandl, 2015) and has brought new light into initial steps and dynamics during the foundation and spread of new apomictic populations. Here we review main findings about the rise and dynamics of apomixis in natural plant populations.

\section{THE FOUNDATIONAL PHASE: THE EMERGENCE OF AN APOMICTIC INDIVIDUAL}

Despite decades of research, it is still unclear how apomixis originates de novo in natural populations. Two main possibilities can be envisioned: either, seeds are dispersed from an apomictic source population, and the seedlings would find a new apomictic population; or, a spontaneous shift to apomixis happens in an otherwise sexually reproducing individual. The first case is difficult to trace in plants, as neither seed dispersal nor pollen dispersal can be easily documented in natural populations. Establishment of an apomictic newcomer in an otherwise sexual population is also hampered by minority effects (see below), and reduced fecundity (Hörandl and Temsch, 2009). Of course, the first scenario shifts the natural origin of apomixis just to another source population.

For the spontaneous de novo emergence of apomixis in natural populations, different hypotheses have been proposed. Traditionally, hybridization was regarded as a main trigger for emergence of apomixis (Ernst, 1918; Asker and Jerling, 1992; Carman, 1997). Evidence for hybrid origin of natural apomictic taxa is available in an increasing number of molecular studies (e.g., Koch et al., 2003; Paun et al., 2006; Lo et al., 2010; Beck et al., 2012; Šarhanová et al., 2017). The emergence of apomixis in hybrids has been confirmed even for diploid species. In fact, almost all natural diploid apomictic species in the genus Boechera are hybrids (Kantama et al., 2007; Aliyu et al., 2010; Beck et al., 2012). Synthetic diploid $\mathrm{F}_{1}$ hybrids in the Ranunculus auricomus complex of diploid, obligate sexual parental species showed spontaneous emergence of apospory in first hybrid generation (Hojsgaard et al., 2014a), and increased frequencies of apospory and first functional apomictic seeds in the diploid $\mathrm{F}_{2}$ (Barke et al., 2018). These studies also shed light on the open question why only few plant hybrid combinations would express spontaneous apomixis: hybridization appears to affect only one component of apomixis, i.e., the formation of an unreduced embryo sac from a diplosporous or aposporous initial cell. The other steps of apomictic seed formation, namely parthenogenesis and endosperm formation, are apparently not influenced by hybridization (Barke et al., 2018). 


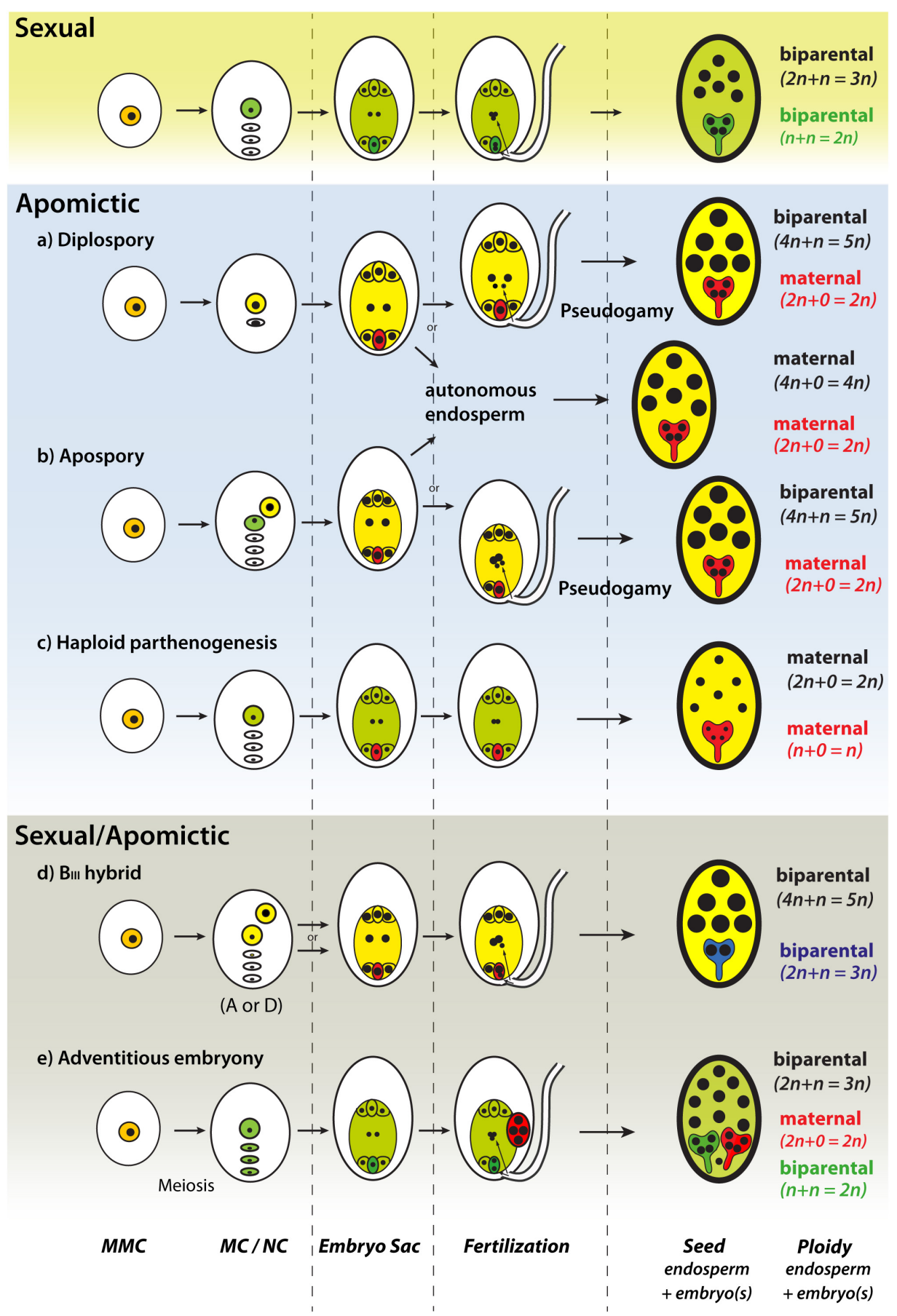

FIGURE 1 | Main developmental pathways of natural apomixis in flowering plants (adapted from Hörandl, 2018). Meiotic developmental pathways (c,e) and biparental seed development (d,e) (green gametophytes, embryo, and endosperm tissues); apomictic developmental pathways (a,b,d) and maternal seed development $\mathbf{( a - c , e ) ~ ( y e l l o w ~ g a m e t o p h y t e s ~ a n d ~ e n d o s p e r m ~ t i s s u e , ~ r e d ~ e g g - c e l l ~ a n d ~ e m b r y o ~ t i s s u e ) ; ~ b l u e ~ s e e d ~ e m b r y o ~ i s ~ d e r i v e d ~ f r o m ~ a ~ f e r t i l i z e d ~ u n r e d u c e d ~}$ egg-cell. MMC, megaspore mother cell; MC, megaspore; NC, nucellus cell; $B_{\text {III }}$ hybrid, offspring produced by fertilization of unreduced egg cells. Size of nuclei corresponds to relative ploidy level.

Other authors focused on polyploidization, following the observation that almost all natural apomictic plant populations are polyploids. Polyploidy could result in a "genomic shock" and genome-wide changes of gene expression (Koltunow and Grossniklaus, 2003). Carman (1997) developed the most comprehensive theory for polyploidization being the trigger for natural apomixis: climatic fluctuations during the Pleistocene would have caused range shifts and secondary 
contact hybridization of different ecotypes; the subsequent changes in timing of gene expression patterns in the cascade of megasporogenesis-megagametogenesis would be changed so that the megasporogenesis phase would be skipped, resulting in suppression of sexuality and expression of apomixis. In principle this could also happen after autopolyploidization in duplicated genes. Developmental and transcriptomic studies in fact revealed signs of asynchrony of gene expression in apomictic development (e.g., Polegri et al., 2010; Sharbel et al., 2010). In Paspalum notatum, artificial polyploidization led to the expression of apomixis in two synthetic autotetraploids while a third induced autopolyploid remained sexual (Quarin et al., 2001). Likewise, other autopolyploid Paspalum species, e.g., $P$. plicatulum and $P$. simplex, remained sexual after artificial polyploidization (Sartor et al., 2009).

In natural systems, the effects of polyploidy for the functionality of apomixis are not yet clear. A positive effect of autopolyploidization on establishing higher frequencies of apomictic seed formation has been observed in polyploidized Paspalum rufum (Delgado et al., 2014). Allele dosage effects of apospory or diplospory-specific genomic regions in polyploids on frequencies of apospory/diplospory have been observed in different model systems (Ozias-Akins and van Dijk, 2007). Dosage effects may further enhance development of unreduced embryo sac formation compared to meiotic reduced ones (Sharbel et al., 2010; Hojsgaard et al., 2013). A classical model by Nogler (1984) suggested that the apospory-controlling factors would have lethal effects in haploid gametes, thereby requiring diploid gametes for inheritance. However, this hypothesis was rejected by findings of Barke et al. (2018) that apospory can be inherited by haploid gametes in diploid R. auricomus hybrids.

Moreover, some model systems appear to express apomixis without any signs of hybridity or polyploidy. In Paspalum, many diploid species exhibit development of unreduced female gametophyte at low frequencies (reviewed in Ortiz et al., 2013), some of which seem to be able to have apomictic seed formation (Siena et al., 2008; Ortiz et al., 2013; Delgado et al., 2014, 2016). In the alpine species Ranunculus kuepferi, large scale FCSS screenings revealed spontaneous apomictic seed formation at low frequencies in otherwise sexual, diploid wild populations in the Alps (Schinkel et al., 2016). These diploid populations are not hybrids, they are geographically distant and isolated from each other and from apomictic tetraploids; no apparent dispersal or gene flow could be traced between them in population genetic studies (Cosendai et al., 2013). More detailed FCSS study further contradicted the hypothesis of a contagious origin of apomixis in diploids via pollination from tetraploid apomicts, but rather suggested a female triploid bridge of rare $\mathrm{B}_{I I I}$ hybrid formation, via female unreduced gametes produced by diploid plants (Schinkel et al., 2017; Figure 2). Among tetraploids of $R$. kuepferi, not even a single tetraploid obligate sexual population or individual could be found in the whole range of the species, which contradicts the idea that the shift to apomixis happened after polyploidization. Experimental studies rather suggested that cold shocks and frost treatments during development can increase frequencies of apomictic and also $\mathrm{B}_{I I I}$ seed formation in diploid R. kuepferi (Klatt et al., 2018). Although the frequencies of these events are low, they might be effective in evolutionary time periods.

What actually might trigger unreduced embryo sac formation under natural conditions? The appearance of apospory in otherwise sexual diploid plant species has been reported from Paspalum (reviewed by Ortiz et al., 2013), and in many Asteraceae genera that were otherwise not apomictic (Noyes, 2007). Aposporous initials act as surrogate cells for the meiotic products, or the spores, and ectopic, aposporous cell formation depends on production of a meiotic tetrad in Hieracium (Koltunow et al., 2011). This may not be the case in other apomictic systems like Paspalum, where the MMC often initiates abortion before entering the meiotic division (e.g., Hojsgaard et al., 2008). Cell-to-cell communication and/or direct contact between the emerging aposporous initial cell and the MC appears to take place before the former suppresses development of the latter (Schmidt et al., 2014, 2015; Juranic et al., 2018). Also, restitutional female meiosis, the process resulting in diplospory, is relatively widespread in plants. In Taraxacum, a model with first division restitution, the DIPLOSPORY (DIP) locus could be characterized and located on one NOR chromosome (Vijverberg et al., 2010; Vasut et al., 2014). Restitutional meiosis, however, can also be triggered by extreme temperatures and other environmental factors (De Storme and Geelen, 2013; Mirzaghaderi and Hörandl, 2016). In female development, unreduced MCs just have to develop into unreduced embryo sacs to produce unreduced female gametes. This capacity of unreduced gamete formation fits to the hypothesis discussed by Carman (1997); Hojsgaard et al. (2014b): that all angiosperms may have an inherent potential for shifting to apomixis.

Comparative transcriptomic studies on sexual and apomictic plants suggested that many stress-associated genes are differentially regulated in the premeiotic to gametophytic stage (Sharbel et al., 2010; Schmidt et al., 2014, 2015; Shah et al., 2016; Rodrigo et al., 2017). Prolonged photoperiods triggered increased sexual MC formation in facultative apomictic plants and resulted in reprogramming of secondary metabolite profiles (Klatt et al., 2016). Hence, natural apomeiosis has to be seen in the context of the physiological condition of the plant. This fits to a more general hypothesis that sexuality would have evolved and established early in eukaryote evolution as a DNA repair tool after oxidative stress conditions (Hörandl and Hadacek, 2013; Hörandl and Speijer, 2018). Fluctuating environmental conditions and stress response are hypothesized to be the major natural triggers for expressing the meiotic pathway. This aspect also sheds a new light on the putative role of polyploidy on expression of apomixis. Polyploids in general better regulate environmentally induced stress conditions, showing homeostatic maintenance of reproductive output under elevated abiotic stress, and therefore have a fitness advantage over diploids in climatically variable or extreme habitats (Schoenfelder and Fox, 2015). Hence, low stress conditions in polyploid reproductive tissues would stimulate the sexual meiotic pathway in archesporial cells to a lesser extent, thereby releasing the inherent potential of plants for apomeiosis (Hörandl and Hadacek, 2013).

In wild populations, the spontaneous appearance of the fully functional apomictic pathway is probably limited by the failure of 


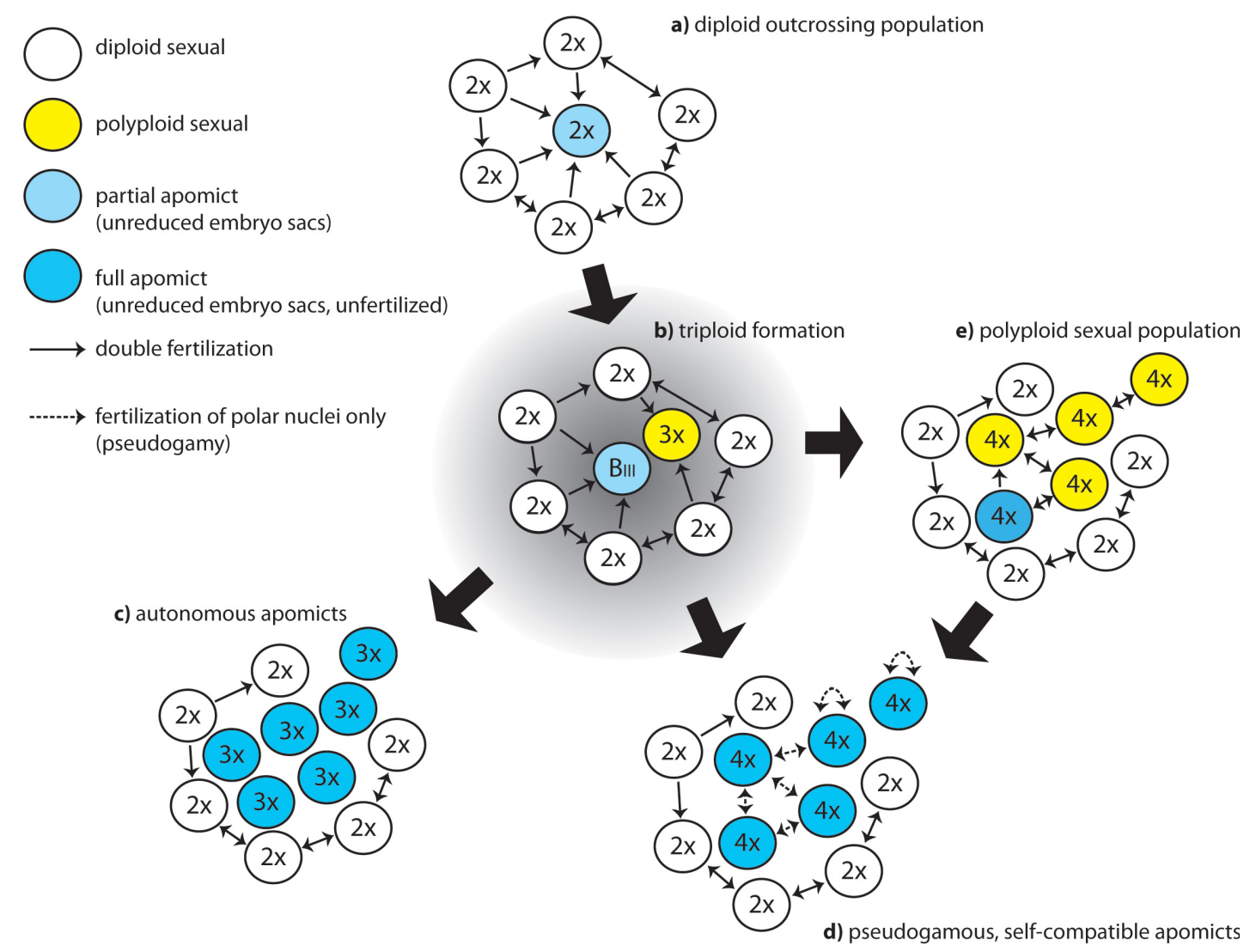

FIGURE 2 | Hypothetical scheme of evolutionary pathways to apomixis in natural populations. (a) starting population; (b) emergence of apomixis elements and rise of first polyploid plants; (c) stabilization of functional, pollen-independent apomixis in triploids; (d) formation of even-ploid apomictic, pseudogamous polyploids; (e) formation of even polyploids and reversal to sexual reproduction.

connecting unreduced gamete formation to parthenogenesis and endosperm formation. Parthenogenesis itself is a process which again may occur spontaneously in natural populations. Again, the totipotency of plant cells allows for embryogenesis to start from different cell types, be it fertilized or unfertilized egg cells, somatic cells, or can be even induced in other tissues like microspores (Soriano et al., 2013). Somatic embryogenesis is in Paspalum associated with SOMATIC EMBRYOGENESIS RECEPTORLIKE KINASE (SERK) genes, and altered temporal and spatial expression of SERK gene copies appear to be associated with apomixis (Podio et al., 2014b). In apomictic Paspalum plants, cytosine-methylations inactivate genes that otherwise repress parthenogenesis (Podio et al., 2014a). In Pennisetum and in Brachiaria, the ASGR-BABY BOOM-like (ASGR-BBML) gene could be identified to control parthenogenesis (Conner et al., 2015; Worthington et al., 2019). In rice, ectopic expression of the BABY BOOM1 (BBM1) gene results in parthenogenesis (Khanday et al., 2019). In Hieracium subg. Pilosella, LOSS OF APOMEIOSIS (LOA) and LOSS OF PARTHENOGENESIS (LOP) loci control apomixis, whereby gametophytic expression of LOP is required for both parthenogenesis and endosperm formation (Koltunow et al., 2011). The endosperm and parthenogenesis loci are linked but separate (Ogawa et al.,
2013). In apomictic Boechera, genomic imprinting appears to be involved in the expression of parthenogenesis (Kirioukhova et al., 2018). In sexual Boechera species, paternal and maternal alleles are expressed for embryogenesis, while in parthenogenetic taxa, maternal expression of the PHERES1 gene is drastically increased compared to sexual species. The changes in expression are probably due to altered DNA methylations. Reduced expression of Methyltransferase1 (MET1) and increased expression of Domains-arranged-Methyltransferases (DRM2) will cause cytosin-demethylations, resulting in the observed high expression levels of maternal PHERES1 alleles (Kirioukhova et al., 2018).

In natural populations, haploid parthenogenesis has been reported as a rare event from many plants that is rarely successful (Asker and Jerling, 1992). Haploid embryos probably suffer too much from having just one chromosome set to establish a haploid progeny in natural environments. Polyhaploid progeny, however, was achieved in higher frequencies from $7 \mathrm{x}$ or 8x mother plants in Hieracium (Rosenbaumova et al., 2012). The authors suggested precocious embryogenesis controlled by gametophytes as a putative mechanism. Frequencies of polyhaploids in apomictic plant seed progenies are often very low $(<5 \%)$ and they usually represent the smallest proportion 
of all developmental pathways (Bicknell et al., 2003; Kaushal et al., 2008; Krahulcova et al., 2011; Schinkel et al., 2017). Timing of pollination appears to be important for the expression of parthenogenesis. In many apomictic species, early proembryos had been observed at blooming (e.g., Cooper and Brink, 1949; Burson and Bennett, 1971; Hojsgaard et al., 2008), indicating accelerated parthenogenetic development in some ovules. Anticipated pollinations in facultative apomictic $P$. notatum were able to unlock the recalcitrant nature of unreduced egg cells to fertilization, increasing the formation of $\mathrm{B}_{\text {III }}$ progeny (Martinez et al., 1994). In a similar experiment but using different plant materials, Espinoza et al. (2002) could show experimentally in P. notatum that early pollination (before anthesis) and also late pollination (after anthesis) increased frequencies of apomictic offspring formation, while pollination during anthesis resulted in higher frequencies of sexual seeds. In natural plant populations, pollination during full anthesis is probably the most frequent "default" situation, because insects will be attracted by full floral displays, and wind-pollination is also most efficient in fully opened spikelets. Hence, pollination during anthesis in apomicts would maximize fertilization of reduced egg cells.

The overall data suggest that differential penetrance of parthenogenesis among ovules, carrying reduced and unreduced female gametophytes, might play a relevant role in creating the observed diversity of seed formation pathways. Under this context, a shift in timing of pollination in natural diploids, presenting low proportions of unreduced gametophytes, can significantly increase the relative success of unreduced gametophyte against reduced ones and favor the formation of asexual seeds. This may explain why the above-mentioned diploids of P. rufum (Delgado et al., 2014) or alpine R. kuepferi produced some fully apomictic seeds under wild conditions (Schinkel et al., 2016) and in experiments (Klatt et al., 2018). Accelerated flower development is a common feature of alpine plants, and a putative adaptation to short vegetation periods in alpine environments, especially in early flowering plants (Körner, 2003). Diploid R. kuepferi flowers directly after snow melting, a time when many insect pollinators are not yet available as a pollen vector. Hence we suppose that delayed pollination can easily happen under natural conditions, favoring occasional parthenogenetic development of unreduced egg cells. Further experimental work will be needed to understand the appearance of parthenogenesis under natural conditions.

Endosperm formation is under a different genetic or epigenetic control and is dependent on fertilization of polar nuclei (pseudogamy) in most natural apomicts. Therefore the endosperm and parthenogenesis loci are linked but separate. In Asteraceae, tissues in the ovule other than endosperm appear to provide sufficient nutrients for the embryo (Cooper and Brink, 1949). Likewise, plant families without endosperm formation in the seeds, i.e., Melastomataceae and Orchidaceae, can apparently express autonomous apomixis (Renner, 1989; Teppner, 1996; Zhang and Gao, 2018). Hence autonomous apomixis might evolve when the selective force for endosperm formation is weak. Pseudogamy, however, is predominant in most other families (Mogie, 1992) and is an important constraint for successful seed formation. Some species are sensitive to deviations from an 2 maternal : 1 paternal genome contribution in the endosperm while others are more tolerant (Talent and Dickinson, 2007). Precocious embryo development combined to late pollination would probably indirectly favor double fertilization of polar nuclei, as no receptive egg cells would be available when pollen tubes reach the micropyle. Both sperm nuclei would be directed to fertilize polar nuclei, which has, in Polygonum type embryo sacs, positive effects on endosperm development by maintaining 2 maternal : 1 paternal genome ratios (see above).

Taken together, the coupling of three developmental steps for functional apomictic seed formation is probably realized unfrequently in natural populations. The need of combining mutations for at least three developmental steps makes a mutagenic origin of apomixis in nature very unlikely, as each single component would be selected against (Van Dijk and Vijverberg, 2005). It rather seems that a coincidence of environmental conditions might alter developmental gene expression patterns, resulting in rare apomictic seed formation. Since apomeiosis avoids meiotic "resetting" of DNA methylation patterns (see Paszkowski and Grossniklaus, 2011), altered epigenetic states might be inherited in clonal seeds and may establish apomictic progeny.

Sporophytic apomixis, also called adventitious embryony includes embryogenesis out of somatic tissues of the nucellus or the integuments (Naumova, 1992). Apomictic embryos often develop from several initial cells in parallel or after sexual embryogenesis, resulting in more than one seedling within a seed (polyembryony). Although adventitious embryony is taxonomically the most widespread developmental pathway of apomixis (Hojsgaard et al., 2014b), the genetic control mechanisms are less well studied than in gametophytic apomixis. Because adventitious embryos arise without disturbing the sexual program, its genetic basis is expected to be less complex and a single mutation could initiate somatic embryogenesis. Genomic and transcriptomic analysis of Citrus species revealed 11 candidate loci associated to apomixis. An insertion at the promotor region of CitRWP is associated with polyembryony (Wang et al., 2017). Similar as in gametophytic apomixis, adventitious embryony often appears in polyploids and/or hybrids (Alves et al., 2016; Mendes et al., 2018), but also in diploids or paleopolyploids (Carman, 1997; Whitton et al., 2008).

\section{THE ESTABLISHMENT PHASE: THE FORMATION OF AN APOMICTIC POPULATION}

During this phase, the uncoupled expression of apomixis developmental steps mentioned before is expected to be functional to the establishment of a polyploid apomictic population, required for the survival of the lineage. Uncoupled activation of apomeiosis and parthenogenesis in a diploid cytotype would drive an increase in ploidy and a shift in dosage that can help to stabilize the coordinated expression of apomixis elements and the formation of a number of polyploid individuals producing clonal seeds. In natural conditions, this mostly happens through a triploid intermediary that facilitates the 
formation of even polyploids, like in sexual systems. However, the presence of partial apomixis and uncoupled parthenogenesis can have different outcomes (Figure 2) and foster the establishment of new polyploid populations (Hojsgaard, 2018).

\section{Indirect Effects of Polyploidy}

Polyploidization might have manifold indirect, positive effects on establishing apomictic individuals: first, polyploidy creates an immediate reproductive barrier against the diploid parental and progenitor population; second, polyploidy may cause a breakdown of genetic self-incompatibility (SI) systems which is needed to establish self-fertility of pseudogamous apomicts; and third, polyploidy could indirectly help to establish an apomictic cytotype in a novel ecological niche by changing the overall physiological features and adaptive potentials of the plants.

The interactions of cytotypes in populations with mixed cytotypes will likely lead to polyploidization of the offspring rather than increasing frequencies of occasional diploid apomictic individuals in a population. The following process can be envisioned: the appearance of a diploid apomeiotic individual within an otherwise diploid sexual, self-incompatible population will initially lead to a minority cytotype disadvantage (Levin, 1975), because mostly haploid pollen from the majority of surrounding sexual plants will be transferred to its stigmas (Figure 2a). The apomictic, diploid pioneer-producing unreduced embryo sacs will probably be mostly cross-fertilized and produce triploid $\mathrm{B}_{I I I}$ hybrid offspring, which means that hardly any diploid apomictic progeny can be formed (Figure 2b). In natural diploid populations, identification of apomictic progeny is difficult but feasible using the appropriate molecular approaches (e.g., Siena et al., 2008) or flow cytometric seed screenings (Schinkel et al., 2016). The experimental evidence support the mentioned idea of constraints to the formation of diploid apomictic progeny in nature (Siena et al., 2008; Hojsgaard et al., 2014a; Barke et al., 2018). An exceptional case is represented by apomictic diploids from Boechera. Different species within Boechera show a complex evolutionary history of hybridization and polyploidy, in which -besides the occurrence of apomictic triploids- diploid cytotypes can be sexual or apomictic, the latter being able to produce apomictic seeds recurrently (Aliyu et al., 2010). For details about the possible origin of the patterns of reproductive mode and ploidy variation observed across Boechera see Lovell et al. (2013). Once the mentioned $\mathrm{B}_{I I I}$ triploids are produced, apomeiosis may be more successful for female unreduced gamete formation as it circumvents meiosis dysfunction and the formation of aneuploid gametes. Microsporogenesis and pollen formation, however, will mostly fail producing an array of genetically and chromosomally unbalanced gametes rendering fertilizations unsuccessful, as observed in sexual triploids (e.g., Duszynska et al., 2013). Only parthenogenetic eutriploid embryos would develop, further skipping the molecular consequences of unbalanced genes and chromosomes observed in aneuploid embryos (Birchler and Veitia, 2012). When pollen is not essential for endosperm formation, as it is the case in most Asteraceae, then a triploid, pollen-sterile, highly obligate apomictic lineage would rapidly become established by selection against the sexual pathway (Figure 2c). This scenario is confirmed by the occurrence of different natural populations of triploid apomicts showing autonomous endosperm development in Erigeron (Noyes and Rieseberg, 2000), Hieracium (Bicknell et al., 2000), Taraxacum (Tas and van Dijk, 1999), and by a mathematical model for origins of 3x Taraxacum clones (Muralidhar and Haig, 2017). Recurrent formation of novel $3 \mathrm{x}$ dandelion clones can happen in mixed sexual/apomictic populations (Martonfiova, 2015). In pseudogamous diploid apomicts, triploid $\mathrm{B}_{I I I}$ cytotypes would probably not readily establish a population unless requirements for parental genomic contributions are relaxed, because pollen formation will be heavily disturbed in triploids and hamper proper endosperm formation. However, fertilization of unreduced $3 \mathrm{x}$ egg cells with well-developed haploid pollen from surrounding diploid sexuals can result in tetraploid plants in the next generation, as experimentally observed in most apomicts (Martínez et al., 2007; Hojsgaard et al., 2014a). In tetraploids, meiosis and pollen production is expected to be more stable, and diploid pollen will be available for pseudogamy. When the capacity for apomeiosis was inherited from the triploid mother, and coupling to parthenogenesis is successful, an apomictic tetraploid offspring could originate via a female triploid bridge (Figure 2d), as observed in R. kuepferi (Schinkel et al., 2017), P. simplex (Urbani et al., 2002) and likely in all apomictic systems where occasional triploids had been recorded in natural populations. Alternatively, if during the phase of establishment of the new population, apomixis cannot be stabilized in the new tetraploids but instead meiosis is re-installed and coupled to syngamy (Figure 2e), then sexual polyploidization could be the consequence of this transient $\mathrm{B}_{I I I}$ hybrid (Hojsgaard, 2018).

In some apomictic systems, sexual cytotypes are polyploid and no evidence of occurrence of diploid cytotypes is found in nature. Here we might consider two alternative explanations. In one case, sexual diploids could first undergo sexual polyploidization via unreduced male gametes fertilizing reduced egg cells (male triploid bridge) (De Storme and Geelen, 2013), and then become extinct. The second possibility is that a polyploid apomict in an agamic complex reverts to sexuality, while diploid sexuals become extinct, and then it produces higher ploidy apomictic cytotypes by repeating the cycle. In both cases, among sexual tetraploids, a similar mechanism of rare apomictic seed formation as in diploids might start from predominantly sexual tetraploid populations, like in Potentilla puberula, where just single individuals showed some apomixis, whereas predominant apomixis occurred in cytotypes with higher ploidies (5x to 8x cytotypes; Dobes et al., 2013). Once the high polyploid apomictic lineage is established, heteroploid cross-fertilizations will rather negatively influence fertility of the lower-ploid sexuals, but not the fitness of the higher ploid apomictic plants (Dobes et al., 2018). A similar cytotype distribution and reproductive features was observed, for example, in $H$. pilosella (=Pilosella officinarum; Mráz et al., 2008), in Paspalum durifolium or in P. ionanthum (Ortiz et al., 2013). Seed abortion in sexuals after heteroploid cross-fertilization versus high female fitness after homoploid crosses, but also induced selfing (Mentor effects), 
can contribute to maintenance of diploid sexual populations (Hörandl and Temsch, 2009).

An important side-effect of polyploidization is breakdown of SC systems (SI), resulting in self-fertility, as it is also well known from sexual polyploids (Comai, 2005; Hörandl, 2010). SI systems act in the stigma and in the style, and have a genetic control independent from embryo sac development by S-alleles (de Nettancourt, 2001). Nevertheless, an important selective mechanism can help to establish polyploid, pseudogamous, selfcompatible (SC) clonal lineages: a self-incompatible apomictic plant can neither use its own pollen, nor the pollen of genetically identical clone-mates around, because the $\mathrm{S}$ allele configuration will be the same in surrounding clone-mates. In contrast, an apomictic self-compatible pioneer plant can not only use self-pollen for pseudogamy, it can also use pollen of surrounding clone-mates with identical genotypes for seed production (Hörandl, 2010). In this way, the newly formed selfcompatible polyploid clone becomes completely independent from pollen of surrounding sexual progenitors (Figure 2d). By using self-pollen, an appropriate endosperm balance can also be more easily achieved. Self-fertility with pseudogamy further avoids the negative effects of sexual selfing, namely loss of heterozygosity and inbreeding depression (Hörandl, 2010). Selffertility is further beneficial for founding new populations by single or few founders, even after long distance dispersal of seeds (Baker, 1967; Hörandl, 2006; Cosendai et al., 2013).

Taken together, a couple of internal and external factors have to coincide to combine the different steps of apomixis. Under natural conditions, functional apomictic seed formation in diploids probably requires certain altered ecological conditions, and successful polyploidization for establishment. The rarity of events, which have to be combined, may also cause the low actual frequencies of natural apomixis in angiosperms (see Hojsgaard et al., 2014b for a recent review).

\section{THE DIVERSIFICATION PHASE: RANGE EXPANSION AND SPECIATION OF APOMICTS}

Once an apomictic polyploid population is established, its survival will depend upon the neopolyploids' capacity to either outcompete parental diploids, or move into another habitat. The occupation of a novel ecological niche is in many cases a side-effect of polyploidy. As discussed above, polyploidy perse alters many physiological and cellular features, which may be advantageous in a novel environment. This aspect has attracted much attention in the past, and some authors have seen the ecological potential of polyploidy as the main factor for the wide distribution of some apomicts (Bierzychudek, 1985). Niche shifts of polyploids compared to diploids have been documented in allopolyploid Crataegus (Coughlan et al., 2017), but also in the autopolyploids R. kuepferi (Kirchheimer et al., 2016, 2018) and Paspalum intermedium (Karunarathne et al., 2018). These non-hybrid apomicts do not show a pronounced genetic diversification, but nevertheless managed to occupy habitats outside the ecological range of the diploids.
The evidence indicates that polyploid apomicts behave as generalists and are less competitive than specialist diploids in their native range, but they are more competitive in the peripheral areas of parental diploids (Karunarathne et al., 2018), a condition that may prelude ecological differentiation between cytotypes. Together with inherent biological features of apomixis (i.e., reproductive assurance and clonality), ecological niche shift is another important factor for geographical range expansions and diversification of apomicts. If the new apomictic polyploids cannot adapt to novel environmental conditions, their evolutionary potential would likely be restricted. Mau et al. (2015) found widespread niche conservatism between sexual and apomicts, and found that ploidy is a stronger driver for niche divergence compared to reproductive mode in diploid-triploid cytotypes of Boechera, but substantial variation in directions of niche differentiation was found among species. Thus, according to Mau et al. (2015), homoploid apomicts in Boechera are trapped in the ecological niches of their sexual ancestors.

\section{Reproductive Assurance and Clonality}

Self-fertility and apomixis enable plants to form new populations starting with a single individual (Baker, 1955). Thus, plants benefit twice from apomixis. On the one hand, apomixis allows for founder events and spread of species' populations after seed dispersal. On the other hand, apomixis creates clonal offspring and hence it multiplies genotypes, and it is likely that the fittest ones locally will be established by differential seed sets and better competing aptitudes. This double advantage provides plants with better colonizing abilities and both have a relevant impact on genetic variation at population level and in the biogeographic distribution of cytotypes. These combined features contribute to observed patterns of geographical parthenogenesis (e.g., Kearney, 2005; Hörandl, 2006).

\section{Geographical Parthenogenesis}

Asexual animals and plants often have larger distribution areas than their sexual relatives (Kearney, 2005). In plants, the strong co-occurrence of apomixis and polyploidy made it difficult to entangle their effects on colonization patterns (Bierzychudek, 1985; Hörandl, 2006). In the exceptional case of the Boechera holboellii complex, Mau et al. (2015) found stronger evidence for ploidy driven ecological-niche divergence rather than for reproductive systems. Despite the fact that this observation contradicts general and well-supported patterns of geographic parthenogenesis, all other studies suggest apomixis might speed up dispersal and facilitate range expansions in those polyploids. In the alpine species $R$. kuepferi, diploid cytotypes remained in their refugial area in the southwestern Alps, while tetraploids colonized the whole Alps, the Apennines, and Corsica (Cosendai and Hörandl, 2010). Only tetraploids managed to adapt higher elevations and a colder climatic niche (Kirchheimer et al., 2016; Schinkel et al., 2017). A simulation study of recolonization of the Alps revealed strong combinational effects of niche differentiation and mode of reproduction for tetraploids (Kirchheimer et al., 2018). Similarly, in prairies and grasslands that were not associated to icesheet covers during the last glaciation, species also depict 
patterns of unequal geographic distribution between sexual and apomictic cytotypes. In the grass species $P$. intermedium, diploid cytotypes are less geographically expanded than tetraploid cytotypes and located in northern, climatically milder areas within the distribution of the species in South America (Karunarathne et al., 2018). Tetraploids occupied southern areas by better coping with less productive and harsher environmental variation (Karunarathne et al., 2018). Thus, in most plant systems, apomixis promotes range expansions by exploiting the advantages of clonality and polyploidy.

\section{Population Differentiation and Speciation}

As apomixis freezes genetic variation and reduces genotype variability, populations are expected to evolve independently by reduced gene flow. With time they may evolve into populations holding gene pools that are differentiated enough to avoid hybridization via pre- and postzygotic barriers, and geographically distant (isolated) populations may become subspecies or new species (e.g., Arrigo and Barker, 2012). In fact, morphological differentiation is observed within apomictic complexes, whereby facultative apomixis in hybrid species can promote (slow) divergent selection and formation of microspecies (i.e., an apomictic lineage with particular morphology and genetically homogeneous) (e.g., Burgess et al., 2014), causing severe problems in taxonomy. For a detailed analysis on how to treat apomictic taxa and which species concepts to refer to Haveman (2013), Majeský et al. (2017), Hörandl (2018). An alternative would be to have a reversal to sexuality in one of those widespread populations (Hörandl and Hojsgaard, 2012). A shift back to sexual reproduction in a distant population from the parental sexual species of the polyploid apomicts would also allow for independent evolution, the accumulation of genetic and morphological changes and the acquisition pre- and postzygotic barriers to gene flow (Hojsgaard and Hörandl, 2015).

\section{NATURAL VS. CULTIVATED APOMICTIC PLANT SYSTEMS}

Apomictic plant systems produce clones from seeds, a trait that offers enormous potential for the development of cultivars specifically suited to livestock pastures. Natural apomictic populations are dynamic. Evidence suggests that they are often founded by a single individual that multiplies that genotype to establish a small local population. Along time, likely as a response to local edaphic conditions and environmental variation, the population acquires variation mainly due to residual sexuality and spontaneous mutations. Thus, natural apomictic populations are genotypically diverse (e.g., Daurelio et al., 2004; Paun et al., 2006).

Cultivated crops consist of genetically highly uniform individuals, usually derived from crosses between inbreed lines or highly selected heterozygous plant materials. In this sense, apomictic natural populations with genetically uniform clone-mates and pedigree cultivars of apomictic forage grasses are qualitatively similar, and to some extend comparable to cultivated crop fields with variable levels of heterozygosity and a contrasting type of reproduction involve in the formation of the next generation of seeds. Plant reproductive processes, flowering time, formation of floral organs, pollen viability, etc., are strongly influenced by climatic conditions and can affect seed yields and crop performance (Hampton et al., 2016). Climatic factors govern crop growth and development and are subject to spatial changes in both direction and magnitude, making necessary fine scale analyses to discern the differential spatial responses of crops to climate variability and their impacts on crop yields (Kukal and Irmak, 2018). Therefore, genetically pure sexual crops and apomictic cultivars are expected to have alike responses to variable environmental conditions which might help us understand the short-term effects of ecological and climatic changes on seed production and crop yields, and estimate potential climate-influenced crop yield gain/loss expected from the transfer of apomixis to main crops. Since most apomicts are facultative, in both natural clonal lineages as in commercial forage cultivars, the formation of low proportions of recombinant progeny is expected to increase genetic heterogeneity and inbreeding which may decrease forage productivity. Therefore, at least in forage breeding, a proper reproductive characterization of the selected material using multiple experimental approaches can benefit both breeding programs, by knowing potential rates of hybridization and trait introgression, and field management strategies by estimating proportions of non-maternal offspring expected per generation (Hojsgaard et al., 2016).

Most natural apomicts maintain the pollen function for pseudogamy. For apomictic crops, this means that they could act as pollen donors and introgress adjacent sexual crop stands (van Dijk and van Damme, 2000). To avoid introgression of apomictic variants into sexual ones, apomictic crops would have to be pollen-sterile. However, natural systems show us that the pollen function can be only abandoned with autonomous apomixis, which occurs mostly in plants with or without a weak endosperm formation (see above). Hence, breeding strategies for pollensterile apomictic cultivars may be most useful for forage plants where the major interest of the farmer is in vegetative growth. But for crops plants which are mostly cultivated for their seed yield, the need of pseudogamy for proper endosperm formation requires functional pollen. Breeding strategies aiming at enforced autogamy (e.g., within cleistogamous spikelets or flowers) in crop variants may help to overcome this problem.

Most domesticated crops are highly dependent on use of high inputs (e.g., fertilizers and herbicides), and therefore an escape from cultivation is less likely than an introgression event to a wild relative species (e.g., Arnaud et al., 2003; Uwimana et al., 2012). In contrast, apomictic forage crops are less dependent on inputs and can both introgress a wild relative and escape from cultivation. The same features that make apomictic crops suitable for development of cultivars also make them better invaders, instigating a potential threat to biodiversity and environmental risk. In Latin America, for example, superior Brachiaria grasses for livestock production have been widely adopted covering approximately 25 million hectares ${ }^{1}$, and many areas of Brazil have been recorded as invasive (Almeida-Neto et al., 2010; under

\footnotetext{
${ }^{1}$ https://ciat.cgiar.org/
} 
the name Urochloa spp. in Zenni and Ziller, 2011). Similar cases are recognized worldwide but little is known about the adverse impacts of such invasions on biodiversity. A comparative study on sexual and apomictic invasive plants showed that the latter have similar abilities for ecological niche shifts and establishment in novel, invaded areas like sexual species (Dellinger et al., 2016). A few studied cases show apomictic grasses dominating invaded habitats and displacing native grasslands (Marshall et al., 2012; Dennhardt et al., 2016). Thus, a better understanding surrounding the origin and dynamics of natural apomictic populations, as well as the variation in the expression of residual sexuality and other sources of genetic variation, can help identify and target effective management actions for apomictic crops, which might currently contribute to the sustainable intensification of forage-based systems.

\section{CONCLUSION AND OUTLOOK FOR FUTURE STUDIES}

Apomixis is a complex, developmental trait expected to have an enormous impact in plant breeding if introduced into main crops, both shortening the time required to develop a new variety and to increase revenues. Currently, apomixis is exploited for the creation of forage cultivars but reports documenting, e.g., lack of genetic homogeneity and genetic erosion in those cultivars are not available. Although eclipsed for a long time, the mechanisms responsible for the rise and dynamics of apomixis in natural plant populations, the potential outcomes of apomixis in natural systems and its role in plant evolution start being disentangled. The knowledge about the genetic and ecological factors governing developmental interactions between meiotic

\section{REFERENCES}

Aliyu, O. M., Schranz, M. E., and Sharbel, T. F. (2010). Quantitative variation for apomictic reproduction in the genus Boechera (Brassicaceae). Am. J. Bot. 97, 1719-1731. doi: 10.3732/ajb.1000188

Almeida-Neto, M., Prado, P. I., Kubota, U., Bariani, J. M., Aguirre, G. A., and Lewinsohn, T. M. (2010). Invasive grasses and native Asteraceae in the Brazilian Cerrado. Plant Ecol. 209, 109-122. doi: 10.1007/s11258-0109727-8

Alves, M. F., Duarte, M. O., Bittencourt, N. S., Oliveira, P. E., and Sampaio, D. S. (2016). Sporophytic apomixis in polyembryonic Handroanthus serratifolius (Vahl) SO Grose (Bignoniaceae) characterizes the species as an agamic polyploid complex. Plant Syst. Evol. 302, 651-659. doi: 10.1007/s00606-0161291- 1299

Arrigo, N., and Barker, M. S. (2012). Rarely successful polyploids and their legacy in plant genomes. Curr. Opin. Plant Biol. 15, 140-146. doi: 10.1016/j.pbi.2012. 03.010

Arnaud, J. F., Viard, F., Delescluse, M., and Cuguen, J. (2003). Evidence for gene flow via seed dispersal from crop to wild relatives in Beta vulgaris (Chenopodiaceae): consequences for the release of genetically modified crop species with weedy lineages. Proc. Biol. Sci. 270, 1565-1571. doi: 10.1098/rspb. 2003.2407

Asker, S., and Jerling, L. (1992). Apomixis in Plants. Boca Raton, FL: CRC press.

Baker, H. G. (1955). Self-Compatibility and establishment after 'Long-Distance' dispersal. Evolution 9, 347-349. doi: 10.2307/2405656

Baker, H. G. (1967). Support for Baker's law-as a rule. Evolution 21, 853-856. doi: 10.1111/j.1558-5646.1967.tb03440.x and apomictic pathways, as well as the population dynamics at local and regional scales can not only help us to decipher the strategies plants use to respond and adapt to the environment, but it also provides valuable information to use on apomictic crop management and production practices.

\section{DATA AVAILABILITY}

No original datasets were produced for this article.

\section{AUTHOR CONTRIBUTIONS}

All authors listed have made a substantial, direct and intellectual contribution to the work, and approved it for publication.

\section{FUNDING}

Basic research to this manuscript was funded by the German Research Foundation Deutsche Forschungsgemeinschaft (DFG) (projects Ho 4395/4-1, Ho 4395/1-2 to EH and project Ho5462/1-1 to DH).

\section{ACKNOWLEDGMENTS}

We thank the series editors Emidio Albertini and Fulvio Pupilli for the invitation to present this review article, and reviewers for their valuable comments on the manuscript. We acknowledge support by the Open Access Publication Funds of the Göttingen University.

Barke, H., Daubert, M., and Hörandl, E. (2018). Establishment of apomixis in diploid F2 hybrids and inheritance of apospory from F1 to F2 hybrids of the Ranunculus auricomus complex. Front. Plant Sci. 9:1111. doi: 10.3389/fpls.2018. 01111

Beck, J. B., Alexander, P. J., Allphin, L., Al-Shehbaz, I. A., Rushworth, C., Bailey, C. D., et al. (2012). Does hybridization drive the transition to asexuality in diploid Boechera? Evolution 66, 985-995. doi: 10.1111/j.1558-5646.2011.01507.x

Bicknell, R. A., Borst, N. K., and Koltunow, A. M. (2000). Monogenic inheritance of apomixis in two Hieracium species with distinct developmental mechanisms. Heredity 84, 228-237. doi: 10.1046/j.1365-2540.2000.00663.x

Bicknell, R. A., Lambie, S. C., and Butler, R. C. (2003). Quantification of progeny classes, in two facultatively apotnictic accessions of Hieracium. Hereditas 138, 11-20. doi: 10.1034/j.1601-5223.2003.01624.x

Bierzychudek, P. (1985). Patterns in plant parthenogenesis. Experientia 41, 1255-1264. doi: 10.1007/BF01952068

Birchler, J. A., and Veitia, R. A. (2012). Gene balance hypothesis: connecting issues of dosage sensitivity across biological disciplines. Proc. Natl. Acad. Sci. U.S.A. 109, 14746-14753. doi: 10.1073/pnas.1207726109

Bradford, H. G., and Nonogaki, H. (2007). Seed Development, Dormancy and Germination. Oxford: Wiley-Blackwell. doi: 10.1002/9780470988848

Burgess, M. B., Cushman, K. R., Doucette, E. T., Talent, N., Frye, C. T., and Campbell, C. S. (2014). Effects of apomixis and polyploidy on diversification and geographic distribution in Amelanchier (Rosaceae). Am. J. Bot. 101, 13751387. doi: 10.3732/ajb.1400113

Burson, B. L., and Bennett, H. W. (1971). Chromosome numbers, microsporogenesis, and mode of reproduction of 7 Paspalum species. Crop Sci. 11, 292-294. doi: 10.2135/cropsci1971.0011183X001100020038x 
Carman, J. G. (1997). Asynchronous expression of duplicate genes in angiosperms may cause apomixis, bispory, tetraspory, and polyembryony. Biol. J. Linn. Soc. 61, 51-94. doi: 10.1111/j.1095-8312.1997.tb01778.x

Chapman, M. A., and Burke, J. M. (2006). Letting the gene out of the bottle: the population genetics of genetically modified crops. New Phytol. 170, 429-443. doi: 10.1111/j.1469-8137.2006.01710.x

Comai, L. (2005). The advantages and disadvantages of being polyploid. Nat. Rev. Genet. 6, 836-846. doi: 10.1038/nrg1711

Conner, J. A., Mookkan, M., Huo, H. Q., Chae, K., and Ozias-Akins, P. (2015). A parthenogenesis gene of apomict origin elicits embryo formation from unfertilized eggs in a sexual plant. Proc. Natl. Acad. Sci. U.S.A. 112, 1120511210. doi: 10.1073/pnas.1505856112

Cooper, D. C., and Brink, R. A. (1949). The endosperm-embryo relationship in an autonomous apomict, Taraxacum officinale. Bot. Gaz. 111, 139-153. doi: $10.1086 / 335582$

Cosendai, A. C., and Hörandl, E. (2010). Cytotype stability, facultative apomixis and geographical parthenogenesis in Ranunculus kuepferi (Ranunculaceae). Ann. Bot. 105, 457-470. doi: 10.1093/aob/mcp304

Cosendai, A. C., Wagner, J., Ladinig, U., Rosche, C., and Hörandl, E. (2013). Geographical parthenogenesis and population genetic structure in the alpine species Ranunculus kuepferi (Ranunculaceae). Heredity 110, 560-569. doi: 10. 1038/hdy.2013.1

Coughlan, J. M., Han, S., Stefanovic, S., and Dickinson, T. A. (2017). Widespread generalist clones are associated with range and niche expansion in allopolyploids of Pacific Northwest Hawthorns (Crataegus L.). Mol. Ecol. 26, 5484-5499. doi: 10.1111/mec.14331

Daurelio, L. D., Espinoza, F., Quarin, C. L., and Pessino, S. C. (2004). Genetic diversity in sexual diploid and apomictic tetraploid populations of Paspalum notatum situated in sympatry or allopatry. Plant Syst. Evol. 244, 189-199. doi: 10.1007/s00606-003-0070-6

de Nettancourt, D. (2001). Incompatibility and Incongruity in Wild and Cultivated Plants. Berlin: Springer. doi: 10.1007/978-3-662-04502-2

De Storme, N., and Geelen, D. (2013). Sexual polyploidization in plants cytological mechanisms and molecular regulation. New Phytol. 198, 670-684. doi: $10.1111 /$ nph. 12184

Delgado, L., Galdeano, F., Sartor, M. E., Quarin, C. L., Espinoza, F., and Ortiz, J. P. A. (2014). Analysis of variation for apomictic reproduction in diploid Paspalum rufum. Ann. Bot. 113, 1211-1218. doi: 10.1093/ aob/mcu056

Delgado, L., Sartor, M. E., Espinoza, F., Soliman, M., Galdeano, F., and Ortiz, J. P. A. (2016). Hybridity and autopolyploidy increase the expressivity of apospory in diploid Paspalum rufum. Plant Syst. Evol. 302, 1471-1481. doi: 10.1007/s00606016-1345-z

Dellinger, A. S., Essl, F., Hojsgaard, D., Kirchheimer, B., Klatt, S., Dawson, W., et al. (2016). Niche dynamics of alien species do not differ among sexual and apomictic flowering plants. New Phytol. 209, 1313-1323. doi: 10.1111/nph. 13694

Dennhardt, L. A., Dekeyser, E. S., Tennefos, S. A., and Travers, S. E. (2016). There is no evidence of geographical patterning among invasive kentucky bluegrass (Poa pratensis) populations in the northern great plains. Weed Sci. 64, 409-420. doi: 10.1614/WS-D-15-00169.1

Dirks, R., van Dun, K., de Snoo, C. B., van den Berg, M., Lelivelt, C. L. C., Voermans, W., et al. (2009). Reverse breeding: a novel breeding approach based on engineered meiosis. Plant Biotechnol. J. 7, 837-845. doi: 10.1111/j.14677652.2009.00450.x

Dobes, C., Milosevic, A., Prohaska, D., Scheffknecht, S., Sharbel, T. F., and Hulber, K. (2013). Reproductive differentiation into sexual and apomictic polyploid cytotypes in Potentilla puberula (Potentilleae, Rosaceae). Ann. Bot. 112, 1159-1168. doi: 10.1093/aob/mct167

Dobes, C., Scheffknecht, S., Fenko, Y., Prohaska, D., Sykora, C., and Hülber, K. (2018). Asymmetric reproductive interference: the consequences of crosspollination on reproductive success in sexual-apomictic populations of potentilla puberula (Rosaceae). Ecol. Evol. 8, 365-381. doi: 10.1002/ece3.3684

Duszynska, D., Mckeown, P. C., Juenger, T. E., Pietraszewska-Bogiel, A., Geelen, D., and Spillane, C. (2013). Gamete fertility and ovule number variation in selfed reciprocal F1 hybrid triploid plants are heritable and display epigenetic parent-of-origin effects. New Phytol. 198, 71-81. doi: 10.1111/nph.12147
Ernst, A. (1918). Bastardierung als Ursache der Apogamie im Pflanzenreich. Jena: G. Fischer.

Espinoza, F., Pessino, S. C., Quarin, C. L., and Valle, E. M. (2002). Effect of pollination timing on the rate of apomictic reproduction revealed by RAPD markers in Paspalum notatum. Ann. Bot. 89, 165-170. doi: 10.1093/ $\mathrm{aob} / \mathrm{mcf0} 24$

Figueiredo, D. D., and Kohler, C. (2018). Auxin: a molecular trigger of seed development. Genes Dev. 32, 479-490. doi: 10.1101/gad.312546.118

Gupta, A. K. (2004). Origin of agriculture and domestication of plants and animals linked to early Holocene climate amelioration. Curr. Sci. 87, 54-59.

Hampton, J. G., Conner, A. J., Boelt, B., Chastain, T. G., and Rolston, P. (2016). Climate change: seed production and options for adaptation. Agriculture 6:33. doi: 10.3390/agriculture6030033

Haveman, R. (2013). Freakish patterns - species and species concepts in apomicts. Nord. J. Bot. 31, 257-269. doi: 10.1111/j.1756-1051.2013.00158.x

Hojsgaard, D. (2018). Transient activation of apomixis in sexual neotriploids may retain genomically altered states and enhance polyploid establishment. Front. Plant Sci. 9:230. doi: 10.3389/fpls.2018. 00230

Hojsgaard, D., Greilhuber, J., Pellino, M., Paun, O., Sharbel, T. F., and Hörandl, E. (2014a). Emergence of apospory and bypass of meiosis via apomixis after sexual hybridisation and polyploidisation. New Phytol. 204, 1000-1012. doi: 10.1111/ nph.12954

Hojsgaard, D., Klatt, S., Baier, R., Carman, J. G., and Hörandl, E. (2014b). Taxonomy and biogeography of apomixis in angiosperms and associated biodiversity characteristics. Criti. Rev. Plant Sci. 33, 414-427. doi: 10.1080/ 07352689.2014.898488

Hojsgaard, D., and Hörandl, E. (2015). A little bit of sex matters for genome evolution in asexual plants. Front. Plant Sci. 6:82. doi: 10.3389/fpls. 2015.00082

Hojsgaard, D., Schegg, E., Valls, J. F. M., Martinez, E. J., and Quarin, C. L. (2008). Sexuality, apomixis, ploidy levels, and genomic relationships among four Paspalum species of the subgenus Anachyris (Poaceae). Flora 203, 535-547. doi: 10.1016/j.flora.2007.09.005

Hojsgaard, D. H., Burson, B. L., Quarin, C. L., and Martínez, E. J. (2016). Unravelling the ambiguous reproductive biology of Paspalum malacophyllum: a decades old story clarified. Genet. Resour. Crop Evol. 63, 1063-1071. doi: 10.1007/s10722-015-0303-x

Hojsgaard, D. H., Martinez, E. J., and Quarin, C. L. (2013). Competition between meiotic and apomictic pathways during ovule and seed development results in clonality. New Phytol. 197, 336-347. doi: 10.1111/j.1469-8137.2012. 04381.x

Hörandl, E. (2006). The complex causality of geographical parthenogenesis. New Phytol. 171, 525-538. doi: 10.1111/j.1469-8137.2006.01769.x

Hörandl, E. (2010). The evolution of self-fertility in apomictic plants. Sex. Plant Reprod. 23, 73-86. doi: 10.1007/s00497-009-0122-123

Hörandl, E. (2018). The classification of asexual organisms: old myths, new facts, and a novel pluralistic approach. Taxon 67, 1066-1081. doi: 10.12705/676.5

Hörandl, E., and Hadacek, F. (2013). The oxidative damage initiation hypothesis for meiosis. Plant Reprod. 26, 351-367. doi: 10.1007/s00497-013-0234-237

Hörandl, E., and Hojsgaard, D. (2012). The evolution of apomixis in angiosperms: a reappraisal. Plant Biosyst. 146, 681-693. doi: 10.1080/11263504. 2012.716795

Hörandl, E., and Speijer, D. (2018). How oxygen gave rise to eukaryotic sex. Proc. Biol. Sci. 285:20172706. doi: 10.1098/rspb.2017.2706

Hörandl, E., and Temsch, E. (2009). Introgression of apomixis into sexual species is in the Ranunculus auricomus complex inhibited by mentor effects and ploidy barriers. Ann. Bot. 104, 81-89. doi: 10.1093/aob/mcp093

Juranic, M., Tucker, M. R., Schultz, C. J., Shirley, N. J., Taylor, J. M., Spriggs, A., et al. (2018). Asexual female gametogenesis involves contact with a sexually fated megaspore in apomictic hieracium. Plant Physiol. 177, 1027-1049. doi: 10.1104/ pp. 18.00342

Kantama, L., Sharbel, T. F., Schranz, M. E., Mitchell-Olds, T., de Vries, S., and de Jong, H. (2007). Diploid apomicts of the Boechera holboellii complex display large-scale chromosome substitutions and aberrant chromosomes. Proc. Natl. Acad. Sci. U.S.A. 104, 14026-14031. doi: 10.1073/ pnas.0706647104 
Karunarathne, P., Schedler, M., Martinez, E. J., Honfi, A. I., Novichkova, A., and Hojsgaard, D. (2018). Intraspecific ecological niche divergence and reproductive shifts foster cytotype displacement and provide ecological opportunity to polyploids. Ann. Bot. 121, 1183-1196. doi: 10.1093/aob/ mcy004

Kaushal, P., Malaviya, D. R., Roy, A. K., Pathak, S., Agrawal, A., Khare, A., et al. (2008). Reproductive pathways of seed development in apomictic guinea grass (Panicum maximum Jacq.) reveal uncoupling of apomixis components. Euphytica 164, 81-92. doi: 10.1007/s10681-008-9650-9654

Kearney, M. (2005). Hybridization, glaciation and geographical parthenogenesis. Trends Ecol. Evol. 20, 495-502. doi: 10.1016/j.tree.2005.06.005

Khanday, I., Skinner, D., Yang, B., Mercier, R., and Sundaresan, V. (2019). A maleexpressed rice embryogenic trigger redirected for asexual propagation through seeds. Nature 565, 91-95. doi: 10.1038/s41586-018-0785-788

Kirchheimer, B., Schinkel, C. C. F., Dellinger, A. S., Klatt, S., Moser, D., Winkler, M., et al. (2016). A matter of scale: apparent niche differentiation of diploid and tetraploid plants may depend on extent and grain of analysis. J. Biogeogr. 43, 716-726. doi: 10.1111/jbi.12663

Kirchheimer, B., Wessely, J., Gattringer, G., Hülber, K., Moser, D., Schinkel, C. C. F., et al. (2018). Reconstructing geographical parthenogenesis: effects of niche differentiation and reproductive mode on holocene range expansion of an alpine plant. Eco. Lett. 21, 392-401. doi: 10.1111/ele.12908

Kirioukhova, O., Shah, J. N., Larsen, D. S., Tayyab, M., Mueller, N. E., Govind, G., et al. (2018). Aberrant imprinting may underlie evolution of parthenogenesis. Sci. Rep. 8:10626. doi: 10.1038/s41598-018-27863-27867

Klatt, S., Hadacek, F., Hodac, L., Brinkmann, G., Eilerts, M., Hojsgaard, D., et al. (2016). Photoperiod extension enhances sexual megaspore formation and triggers metabolic reprogramming in facultative apomictic Ranunculus auricomus. Front. Plant Sci. 7:278. doi: 10.3389/fpls.2016.00278

Klatt, S., Schinkel, C. C. F., Kirchheimer, B., Dullinger, S., and Hörandl, E. (2018). Effects of cold treatments on fitness and mode of reproduction in the diploid and polyploid alpine plant Ranunculus kuepferi (Ranunculaceae). Ann. Bot. 121, 1287-1298. doi: 10.1093/aob/mcy017

Koch, M. A., Dobes, C., and Mitchell-Olds, T. (2003). Multiple hybrid formation in natural populations: concerted evolution of the internal transcribed spacer of nuclear ribosomal DNA (ITS) in north American Arabis divaricarpa (Brassicaceae). Mol. Biol. Evol. 20, 338-350. doi: 10.1093/molbev/msg046

Koltunow, A. M., and Grossniklaus, U. (2003). Apomixis: a developmental perspective. Ann. Rev. Plant Biol. 54, 547-574. doi: 10.1146/annurev.arplant. 54.110901 .160842

Koltunow, A. M., Johnson, S. D., Rodrigues, J. C., Okada, T., Hu, Y., Tsuchiya, T., et al. (2011). Sexual reproduction is the default mode in apomictic Hieracium subgenus Pilosella, in which two dominant loci function to enable apomixis. Plant J. 66, 890-902. doi: 10.1111/j.1365-313X.2011.04556.x

Körner, C. (2003). Alpine Plant Life. Functional Plant Ecology of High Mountain Systems. Heidelberg: Springer. doi: 10.1007/978-3-642-18970-8

Krahulcova, A., Krahulec, F., and Rosenbaumova, R. (2011). Expressivity of apomixis in $2 \mathrm{n}+\mathrm{n}$ hybrids from an apomictic and a sexual parent: insights into variation detected in Pilosella (Asteraceae: Lactuceae). Sex. Plant Reprod. 24, 63-74. doi: 10.1007/s00497-010-0152-x

Kukal, M. S., and Irmak, S. (2018). Climate-driven crop yield and yield variability and climate change impacts on the U.S. great plains agricultural production. Sci. Rep. 8, 1-18. doi: 10.1038/s41598-018-21848-2

Lambing, C., Franklin, F. C. H., and Wang, C. J. R. (2017). Understanding and manipulating meiotic recombination in plants. Plant Physiol. 173, 1530-1542. doi: 10.1104/pp.16.01530

Levin, D. A. (1975). Minority cytotype exclusion in local plant populations. Taxon 24, 35-43. doi: 10.2307/1218997

Lo, E. Y. Y., Stefanovic, S., and Dickinson, T. A. (2010). Reconstructing reticulation history in a phylogenetic framework and the potential of allopatric speciation driven by polyploidy in an agamic complex in Crataegus (Rosaceae). Evolution 64, 3593-3608. doi: 10.1111/j.1558-5646.2010.01063.x

Lovell, J. T., Aliyu, O. M., Mau, M., Schranz, M. E., Koch, M., Kiefer, C., et al. (2013). On the origin and evolution of apomixis in Boechera. Plant Reprod. 26, 309-315. doi: 10.1007/s00497-013-0218-7

Majeský, L., Krahulec, F., and Vašut, R. J. (2017). How apomictic taxa are treated in current taxonomy: a review. Taxon 66, 1017-1040. doi: 10.12705/665.3
Marimuthu, M., Jolivet, S., Ravi, M., Pereira, L., Davda, J., Cromer, L., et al. (2011). Synthetic clonal reproduction through seeds. Science 331:876. doi: 10.1126/ science. 1199682

Marshall, V. M., Lewis, M. M., and Ostendorf, B. (2012). Buffel grass (Cenchrus ciliaris) as an invader and threat to biodiversity in arid environments: a review. J. Arid Environ. 78, 1-12. doi: 10.1016/j.jaridenv.2011.11.005

Martínez, E. J., Acuña, C. A., Hojsgaard, D. H., Tcach, M., and Quarin, C. L. (2007). Segregation for sexual seed production in Paspalum as directed by male gametes of apomictic triploid plants. Ann. Bot. 100, 1239-1247. doi: 10.1093/ $\mathrm{aob} / \mathrm{mcm} 201$

Martinez, E. J., Espinoza, F., and Quarin, C. L. (1994). BIII progeny $(2 n+n)$ from apomictic Paspalum notatum obtained through early pollination. J. Hered. 85, 295-297. doi: 10.1093/oxfordjournals.jhered.a111460

Martonfiova, L. (2015). Hybridization in natural mixed populations of sexual diploid and apomictic triploid dandelions (Taraxacum sect. Taraxacum): why are the diploid sexuals not forced out? Folia Geobot. 50, 339-348. doi: 10.1007/ s12224-015-9231-y

Mau, M., Lovell, J. T., Corral, J. M., Kiefer, C., Koch, M. A., Aliyu, O. M., et al. (2015). Hybrid apomicts trapped in the ecological niches of their sexual ancestors. Proc. Natl. Acad. Sci. U.S.A. 112, E2357-E2365. doi: 10.1073/pnas. 1423447112

Mendes, M. G., de Oliveira, A. P., Oliveira, P. E., Bonetti, A. M., and Sampaio, D. S. (2018). Sexual, apomictic and mixed populations in Handroanthus ochraceus (Bignoniaceae) polyploid complex. Plant Syst. Evol. 304, 817-829. doi: 10.1007/ s00606-018-1512-1515

Mieulet, D., Jolivet, S., Rivard, M., Cromer, L., Vernet, A., Mayonove, P., et al. (2016). Turning rice meiosis into mitosis. Cell Res. 26, 1242-1254. doi: 10.1038/ cr.2016.117

Mirzaghaderi, G., and Hörandl, E. (2016). The evolution of meiotic sex and its alternatives. Proc. Biol. Sci. 283:20161221. doi: 10.1098/rspb.2016. 1221

Mogie, M. (1992). The Evolution of Asexual Reproduction in Plants. London: Chapman and Hall.

Mráz, P., Šingliarová, B., Urfus, T., and Krahulec, F. (2008). Cytogeography of Pilosella officinarum (Compositae): altitudinal and longitudinal differences in ploidy level distribution in the Czech Repuplic and Slovakia and the general pattern in europe. Ann. Bot. 101, 59-71. doi: 10.1093/aob $/ \mathrm{mcm} 282$

Muralidhar, P., and Haig, D. (2017). Sexy males and sexless females: the origin of triploid apomicts. Heredity 118, 436-441. doi: 10.1038/hdy.2016.124

Naumova, T. N. (1992). Apomixis in Angiosperms. Nucellar and Integumentary Embryony. Boca Raton, FL: CRC Press.

Nogler, G. A. (1984). Genetics of apospory in apomictic Ranunculus auricomus. 5. Conclusion. Botanica Helvetica 94, 411-422.

Noyes, R. D. (2007). Apomixis in the asteraceae: diamonds in the rough. Funct. Plant Sci. Biotechnol. 1, 207-222.

Noyes, R. D., and Rieseberg, L. H. (2000). Two independent loci control agamospermy (Apomixis) in the triploid flowering plant Erigeron annuus. Genetics 155, 379-390.

Ogawa, D., Johnson, S. D., Henderson, S. T., and Koltunow, A. M. G. (2013). Genetic separation of autonomous endosperm formation (AutE) from the two other components of apomixis in Hieracium. Plant Reprod. 26, 113-123. doi: 10.1007/s00497-013-0214-y

Ortiz, J. P. A., Quarin, C. L., Pessino, S. C., Acuna, C., Martinez, E. J., Espinoza, F., et al. (2013). Harnessing apomictic reproduction in grasses: what we have learned from Paspalum. Ann. Bot. 112, 767-787. doi: 10.1093/aob/ mct152

Ozias-Akins, P., and van Dijk, P. J. (2007). Mendelian genetics of apomixis in plants. Ann. Rev. Genet. 41, 509-537. doi: 10.1146/annurev.genet.40.110405. 09051

Paszkowski, J., and Grossniklaus, U. (2011). Selected aspects of transgenerational epigenetic inheritance and resetting in plants. Current Opinion in Plant Biology 14, 195-203. doi: 10.1016/j.pbi.2011.01.002

Paun, O., Stuessy, T. F., and Hörandl, E. (2006). The role of hybridization, polyploidization and glaciation in the origin and evolution of the apomictic Ranunculus cassubicus complex. New Phytol. 171, 223-236. doi: 10.1111/j.14698137.2006.01738.x 
Podio, M., Caceres, M. E., Samoluk, S. S., Seijo, J. G., Pessino, S. C., Ortiz, J. P. A., et al. (2014a). A methylation status analysis of the apomixis-specific region in Paspalum spp. Suggests an epigenetic control of parthenogenesis. J. Exp. Bot. 65, 6411-6424. doi: 10.1093/jxb/eru354

Podio, M., Felitti, S. A., Siena, L. A., Delgado, L., Mancini, M., Seijo, J. G., et al. (2014b). Characterization and expression analysis of SOMATIC EMBRYOGENESIS RECEPTOR KINASE (SERK) genes in sexual and apomictic Paspalum notatum. Plant Mol. Biol. 84, 479-495. doi: 10.1007/ s11103-013-0146-9

Polegri, L., Calderini, O., Arcioni, S., and Pupilli, F. (2010). Specific expression of apomixis-linked alleles revealed by comparative transcriptomic analysis of sexual and apomictic Paspalum simplex morong flowers. J. Exp. Bot. 61, 1869-1883. doi: 10.1093/jxb/erq054

Quarin, C. L., Espinoza, F., Martinez, E. J., Pessino, S. C., and Bovo, O. A. (2001). A rise of ploidy level induces the expression of apomixis in Paspalum notatum. Sex. Plant Reprod. 13, 243-249. doi: 10.1007/s004970100070

Renner, S. S. (1989). A survey of reporductive biology in neotropical Melastomataceae and Memecyclaceae. Ann. Mo. Bot. Gard. 76, 496-518. doi: $10.2307 / 2399497$

Rodrigo, J. M., Zappacosta, D. C., Selva, J. P., Garbus, I., Albertini, E., and Echenique, V. (2017). Apomixis frequency under stress conditions in weeping lovegrass (Eragrostis curvula). PLoS One 12:e175852. doi: 10.1371/journal. pone. 0175852

Rosenbaumova, R., Krahulcova, A., and Krahulec, F. (2012). The intriguing complexity of parthenogenesis inheritance in Pilosella rubra (Asteraceae, Lactuceae). Sex. Plant Reprod. 25, 185-196. doi: 10.1007/s00497-012-0190-197

Šarhanová, P., Sharbel, T. F., Sochor, M., Vašut, R. J., Dančák, M., and Trávnčèek, B. (2017). Hybridization drives evolution of apomicts in Rubus subgenus Rubus: evidence from microsatellite markers. Ann. Bot. 120, 317-328. doi: 10.1093/ $\mathrm{aob} / \mathrm{mcx} 033$

Sartor, M. E., Quarin, C. L., and Espinoza, F. (2009). Mode of reproduction of colchicine-induced Paspalum plicatulum tetraploids. Crop Sci. 49, 1270-1276. doi: 10.2135/cropsci2008.05.0270

Schinkel, C. C. F., Kirchheimer, B., Dellinger, A. S., Klatt, S., Winkler, M., Dullinger, S., et al. (2016). Correlations of polyploidy and apomixis with elevation and associated environmental gradients in an alpine plant. AoB Plants 8:Iw064. doi: 10.1093/aobpla/plw064

Schinkel, C. C. F., Kirchheimer, B., Dullinger, S., Geelen, D., De Storme, N., and Hörandl, E. (2017). Pathways to polyploidy: indications of a female triploid bridge in the alpine species Ranunculus kuepferi (Ranunculaceae). Plant Syst. Evol. 303, 1093-1108. doi: 10.1007/s00606-017-1435-1436

Schmidt, A., Schmid, M. W., and Grossniklaus, U. (2015). Plant germline formation: common concepts and developmental flexibility in sexual and asexual reproduction. Development 142, 229-241. doi: 10.1242/dev.102103

Schmidt, A., Schmid, M. W., Klostermeier, U. C., Qi, W. H., Guthorl, D., Sailer, C., et al. (2014). Apomictic and sexual germline development differ with respect to cell cycle, transcriptional, hormonal and epigenetic regulation. PLoS Genet. 10:e1004476. doi: 10.1371/journal.pgen.1004476

Schoenfelder, K. P., and Fox, D. T. (2015). The expanding implications of polyploidy. J. Cell Biol. 209, 485-491. doi: 10.1083/jcb.201502016

Shah, J. N., Kirioukhova, O., Pawar, P., Tayyab, M., Mateo, J. L., and Johnston, A. J. (2016). Depletion of key meiotic genes and transcriptome-wide abiotic stress reprogramming mark early preparatory events ahead of apomeiotic transition. Front. Plant Sci. 7:1539. doi: 10.3389/fpls.2016.01539

Sharbel, T. F., Voigt, M. L., Corral, J. M., Galla, G., Kumlehn, J., Klukas, C., et al. (2010). Apomictic and sexual ovules of Boechera display heterochronic global gene expression patterns. Plant Cell 22, 655-671. doi: 10.1105/tpc.109.072223

Siena, L. A., Sartor, M. E., Espinoza, F., Quarin, C. L., and Ortiz, J. P. A. (2008). Genetic and embryological evidences of apomixis at the diploid level in Paspalum rufum support recurrent auto-polyploidization in the species. Sex. Plant Reprod. 21, 205-215. doi: 10.1007/s00497-008-0080-81
Soriano, M., Li, H., and Boutilier, K. (2013). Microspore embryogenesis: establishment of embryo identity and pattern in culture. Plant Reprod. 26, 181-196. doi: 10.1007/s00497-013-0226-227

Talent, N., and Dickinson, T. A. (2007). Endosperm formation in aposporous Crataegus (Rosaceae, Spiraeoideae, tribe Pyreae): parallels to Ranunculaceae and Poaceae. New Phytol. 173, 231-249. doi: 10.1111/j.1469-8137.2006. 01918.x

Tas, I. C. Q., and van Dijk, P. J. (1999). Crosses between sexual and apomictic dandelions (Taraxacum). I. The inheritance of apomixis. Heredity 83, 707-714. doi: 10.1046/j.1365-2540.1999.00619.x

Teppner, H. (1996). Adventitious embryony in Nigritella (Orchidaceae). Folia Geobot. 31, 323-331. doi: 10.1007/bf02815377

Urbani, M. H., Quarin, C. L., Espinoza, F., Penteado, M. I. O., and Rodrigues, I. F. (2002). Cytogeography and reproduction of the Paspalum simplex polyploid complex. Plant Syst. Evol. 236, 99-105. doi: 10.1007/s00606-002-0237-6

Uwimana, B., D’Andrea, L., Felber, F., Hooftman, D. A. P., Den Nijs, H. C. M., Smulders, M. J. M., et al. (2012). A bayesian analysis of gene flow from crops to their wild relatives: cultivated (Lactuca sativa L.) and prickly lettuce (L. serriola L.) and the recent expansion of L. serriola in Europe. Mol. Ecol. 21, 2640-2654. doi: 10.1111/j.1365-294X.2012.05489.x

van Dijk, P., and van Damme, J. (2000). Apomixis technology and the paradox of sex. Trends Plant Sci. 5, 81-84. doi: 10.1016/s1360-1385(99)01545-1549

Van Dijk, P. J., and Vijverberg, K. (2005). "The significance of apomixis in the evolution of the angiosperms: A reappraisal," in Plant Species-level Systematics. New Perspectives on Pattern \& Process, eds F. T. Bakker, L. W. Chatrou, B. Gravendeel, and P. B. Pelser (Ruggell: A.R.G. Gantner Verlag), 101-116.

Vasut, R. J., Vijverberg, K., van Dijk, P. J., and de Jong, H. (2014). Fluorescent in situ hybridization shows DIPLoSPOROUS located on one of the NOR chromosomes in apomictic dandelions (Taraxacum) in the absence of a large hemizygous chromosomal region. Genome 57, 609-620. doi: 10.1139/gen2014-2143

Vijverberg, K., Milanovic-Ivanovic, S., Bakx-Schotman, T., and van Dijk, P. J. (2010). Genetic fine-mapping of DIPLoSPOROUS in Taraxacum (dandelion; Asteraceae) indicates a duplicated DIP-gene. BMC Plant Biol. 10:154. doi: 10. 1186/1471-2229-10- 154

Wang, X., Xu, Y. T., Zhang, S. Q., Cao, L., Huang, Y., Cheng, J. F., et al. (2017). Genomic analyses of primitive, wild and cultivated Citrus provide insights into asexual reproduction. Nat. Genet. 49, 765-772. doi: 10.1038/ng.3839

Whitton, J., Sears, C. J., Baack, E. J., and Otto, S. P. (2008). The dynamic nature of apomixis in the angiosperms. Int. J. Plant Sci. 169, 169-182. doi: 10. $1086 / 523369$

Worthington, M., Ebina, M., Yamanaka, N., Heffelfinger, C., Quintero, C., Zapata, Y. P., et al. (2019). Translocation of a parthenogenesis gene candidate to an alternate carrier chromosome in apomictic Brachiaria humidicola. BMC Genomics 20:41. doi: 10.1186/s12864-018-5392-5394

Zenni, R. D., and Ziller, S. R. (2011). An overview of invasive plants in Brazil. Brazilian J. Bot. 34, 431-446. doi: 10.1590/S0100-84042011000300016

Zhang, W. L., and Gao, J. Y. (2018). High fruit sets in a rewardless orchid: a case study of obligate agamospermy in Habenaria. Aust. J. Bot. 66, 144-151. doi: $10.1071 /$ bt17182

Conflict of Interest Statement: The authors declare that the research was conducted in the absence of any commercial or financial relationships that could be construed as a potential conflict of interest.

Copyright $\odot 2019$ Hojsgaard and Hörandl. This is an open-access article distributed under the terms of the Creative Commons Attribution License (CC BY). The use, distribution or reproduction in other forums is permitted, provided the original author(s) and the copyright owner(s) are credited and that the original publication in this journal is cited, in accordance with accepted academic practice. No use, distribution or reproduction is permitted which does not comply with these terms. 